\title{
Computational interactions between decision and emotion
}

\author{
Nicoladie D Tam \\ From 24th Annual Computational Neuroscience Meeting: CNS*2015 \\ Prague, Czech Republic. 18-23 July 2015
}

\section{Introduction}

Decision is often influenced by emotions, such that the decision can often be biased by the emotional influences, such as happiness, sadness, fear and anger. Previous experimental studies in human subjects have shown that decisions are often related to emotional levels $[1,2]$. It is also often assumed that decision is influenced by emotion, but there is evidence that decision can also influence emotions. Thus, the interrelationship between decision and emotion requires indepth re-examination to determine the interactions between decision and emotion.

\section{Methods:}

A computational model of decision-making relative to emotion is derived based on the experimental evidence of decision in relation to emotion in human subjects. Using the classical behavioral economic experimental Ultimatum Game paradigm [3] that elicits the interrelationship between decision and emotion in human subjects [4-7], a computational model of decision is derived based on the shifting of the threshold in the stimulusresponse function of emotional responses.

\section{Results:}

Using the quantitative analysis, the emotional stimulusresponse function was derived based on the disparity between the desirable predicted outcome and the actual outcome in the real world for happy [4], sad [6], angry [5], jealous [7] emotions and for fairness perception [8], using the optimizations in survival functions $[9,10]$. The relationships between decision and emotions were also established for happy [1] emotion, and for fairness [11]

Correspondence: nicoladie.tam@unt.edu

Department of Biological Sciences, University of North Texas, Denton, TX 76203, USA experimentally, and the interrelationship between decision and fairness was derived computationally [12].

Extending the result to emotions, let $\mathbf{e}$ be the vector representing the emotional intensity, $\mathbf{d}$ be the vector representing the disparity between the predicted outcome and actual outcome, then the emotional stimulusresponse function is given by: $\mathbf{e}=k f(\mathbf{d})+b$ where $f(\cdot)$ represents a nonlinear function, and the coefficient $k$ is the emotional sensitivity and $b$ is the emotional baseline level. Let $\mathbf{x}$ be the vector representing the decision (where $\mathbf{x}=1$ represents a yes decision, and $\mathbf{x}=-1$ represents a no decision), then the decision threshold can be given by: $\mathbf{x}=\left\{\begin{array}{c}1, \text { if } k f(\mathbf{d})+b \geq \theta \\ -1, \text { otherwise }\end{array}\right.$ where is the decision threshold, representing the dependence of decision on emotion.

\section{Discussion:}

The interrelationship between decision and emotion can be derived based on the threshold crossing of the emotional intensity level, in which an emotional bias in either the emotional baseline or the emotional sensitivity can cause a change in decision. The decision is based on the threshold crossing of the emotional stimulusresponse function, such that it is a continuum in altering the decision-making process by the shifting of emotional bias in either emotional baseline or sensitivity.

Published: 18 December 2015

\footnotetext{
References

1. Tam ND: Quantification of happy emotion: Dependence on decisions. Psychol Behav Sci 2014, 3(2):68-74.

2. Tam ND: Rational decision-making process choosing fairness over monetary gain as decision criteria. Psychol Behav Sci 2014, 3(6-1):16-23.

3. von Neumann J, Morgenstern O, Rubinstein A: Theory of games and economic behavior Princeton, NJ: Princeton University Press; 1953.

4. Tam ND: Quantification of happy emotion: Proportionality relationship to gain/loss. Psychol Behav Sci 2014, 3(2):60-67
} 
5. Tam DN: Computation in emotional processing: quantitative confirmation of proportionality hypothesis for angry unhappy emotional intensity to perceived loss. Cogn Comput 2011, 3(2):394-415.

6. Tam ND: Quantitative assessment of sad emotion. Psychol Behav Sci 2014, 4(2):36-43.

7. Tam ND, Smith KM: Cognitive computation of jealous emotion. Psychology and Behavioral Sciences 2014, 3(6-1):1-7.

8. Tam ND: Quantification of fairness perception by including otherregarding concerns using a relativistic fairness-equity model. Adv in Soc Sci Research J 2014, 1(4):159-169.

9. Tam D: EMOTION-I model: A biologically-based theoretical framework for deriving emotional context of sensation in autonomous control systems. The Open Cybernetics and Systemics Journal 2007, 1:28-46.

10. Tam D: EMOTION-II model: A theoretical framework for happy emotion as a self-assessment measure indicating the degree-of-fit (congruency) between the expectancy in subjective and objective realities in autonomous control systems. The Open Cybernetics and Systemics Journal 2007, 1:47-60.

11. Tam ND: Quantification of fairness bias in relation to decisions using a relativistic fairness-equity model. Adv in Soc Sci Research J 2014, 1(4):169-178

12. Tam ND: A decision-making phase-space model for fairness assessment. Psychol Behav Sci 2014, 3(6-1):8-15.

doi:10.1186/1471-2202-16-S1-P244

Cite this article as: Tam: Computational interactions between decision and emotion. BMC Neuroscience 2015 16(Suppl 1):P244.

\section{Submit your next manuscript to BioMed Central and take full advantage of:}

- Convenient online submission

- Thorough peer review

- No space constraints or color figure charges

- Immediate publication on acceptance

- Inclusion in PubMed, CAS, Scopus and Google Scholar

- Research which is freely available for redistribution

Submit your manuscript at www.biomedcentral.com/submit 